\title{
DISCURSO POLÍTICO, MÍDIA E VERDADE ${ }^{1}$
}

\author{
Entrevista com Mariano Dagatti
}

Political discourse, media and truth

\author{
Mariano Dagatti ${ }^{2}$ \\ Universidad Nacional de Quilmes (UNQ - CONICET - UBA)
}

\begin{abstract}
RESUMO: Nesta entrevista, o cientista social e especialista em análise de discurso político Mariano Dagatti aborda suas pesquisas sobre os estilos de comunicação política adotados pelos três últimos presidentes eleitos na Argentina, Néstor Kirchner (de 2003 à 2007), Cristina Fernández (de 2007 a 2015) e Mauricio Macri (de 2015 a 2019). Ele também reflete sobre a relação entre os meios e as instituições de comunicação novos e tradicionais, suas semelhanças e diferenças e sua relação com a política, com a verdade e com o ensino.
\end{abstract}

Palavras-chave: Discurso político; Mídias; Verdade.

ABSTRACT: In this interview, the social scientist presents some results of his research on the political communication styles adopted by the last 3 presidentselect in Argentina, Néstor Kirchner (from 2003 to 2007), Cristina Fernández (from 2007 to 2015), and Mauricio Macri (from 2015 to 2019). He also reflects on the relationship between the media and communication institutions, the traditional and the new ones linked to digital technologies, as well as their differences and similarities in their relationship with politics, with truth and with teaching.

Keywords: Political discourse; Media; Truth.

\footnotetext{
${ }^{1}$ Entrevista realizada no dia 12 de setembro de 2018, durante o V CIAD - Colóquio Internacional de Análise do Discurso: Discurso e (pós)verdade. Efeitos de real e sentidos da conviç̧ão. Na ocasião, o entrevistado proferiu o curso: "Los imaginarios políticos del siglo XXI: retórica visual y hegemonía discursiva en la Argentina contemporánea". A equipe responsável pela produção, transcrição, tradução, retextualização e revisão desta entrevista foi composta por Eder Cavalcanti Coimbra, Leonardo Henrique Breda, Maria Carolina Coradini, Pedro Henrique Turci, Fernanda Rodrigues, Ingrid da Mata, Julia Santana, Karina Rodrigues e Letícia Tizioto, discentes no curso de Bacharelado em Linguística da UFSCar, e Luzmara Curcino e Vanice Sargentini, docentes no Departamento de Letras e no Programa de Pós-graduação em Linguística da UFSCar. A entrevista contou ainda com o apoio técnico de Lívia Maria Falconi Pires, doutora em Linguística pelo PPGL-UFSCar e docente na UNICEP - São Carlos.

${ }^{2}$ Bacharel e Licenciado em Comunicação Social, com especialização em Jornalismo, pela Universidad Nacional de Entre Ríos, tem se dedicado à análise do discurso político na Argentina. Atua como docente no Centro de Pesquisa sobre Economia e Sociedade na Argentina contemporânea (IESAC), da Universidad de Quilmes. É autor do livro El partido de la patria: los discursos presidenciales de Néstor Kirchner (Editora Biblos, 2017), e organizador, com Vanice Sargentini, do livro Los pueblos de la democracia. Politica y médios en el siglo XXI (Editora La Bicicleta, 2018).
} 


\section{Ethos presidencial e comunicação política na Argentina}

Entrevistadores: A comunicação política tem papel decisivo tanto nas disputas eleitorais quanto na gestão de imagem de um governo eleito. Algumas estratégias comunicacionais são relativamente comuns e tradicionais. Outras têm assumido papel importante na constituição de um ethos político adequado ao que se espera dessa figura pública na atualidade. Em suas pesquisas você estabeleceu especificidades do estilo da comunicação política do kirchnerismo e, mais recentemente, do macrismo. Se poderia falar de diferenças de estilo individual desses políticos?

Mariano Dagatti: Num primeiro momento é necessário refletirmos sobre o conceito de 'estilo individual'. Trabalhei com a noção de 'estilo', mas sempre entendida como uma noção que conecta o individual ao social. Nesse sentido, creio que efetivamente existem diferentes estilos. Não me atreveria a afirmar que seriam estilos inteiramente individuais. Parece-me que esses estilos, simultaneamente, correlacionam dimensões físicas, biográficas, estas sim individuais, do orador, com uma série de condições sócio-históricas e de fatores sociais que intervêm na construção de seus estilos.

O Kirchnerismo ${ }^{3}$, com Néstor Kirchner, constituiu ao longo do tempo um estilo que, quando o interpretamos restrospectivamente, tem muitas semelhanças com o estilo que buscou construir Mauricio Macri. Kirchner construiu um estilo presidencial baseado na ideia de que ele era "um homem comum com responsabilidades importantes" e na ideia de que a política se fazia com coragem, com convicções, de que a política se fazia na rua, em contato com o povo, de que o diálogo próximo com a população era um índice fundamental de avaliação política. O seu modelo de político era certamente o do 'militante', e o 'militante' era por definição alguém próximo. Macri também fez da proximidade um valor fundamental do seu estilo de comunicação. Ele se apresentava como um funcionário à serviço da política, sensível às emoções e desejos da população. O ponto em comum, portanto, entre a imagem pública de Néstor Kirchner e Mauricio Macri é aquele que investe na representação da proximidade com o povo, de um contato direto e corpo a corpo com ele, no qual se apagam as assimetrias e se busca construir uma identificação.

\footnotetext{
${ }^{3} \mathrm{O}$ Kirchnerismo compreende o período de governo de Néstor Kirchner, presidente da Argentina entre os anos de 2003 a 2007, e o de sua esposa, Cristina Fernández de Kirchner, que ocupou o cargo de presidenta nos anos de 2007 a 2015.
} 
Quanto a Cristina Fernández, ela enfrentou mais dificuldades do que estes para constituir um estilo preciso, coerente ou, em outros termos, para articular seu estilo pessoal (como líder, como mulher, como militante) com as representações sociais de liderança, da posição das mulheres na política. Para ela, era difícil se mostrar próxima porque, por razões pessoais e sociais extraordinárias, ela era (em sentido literal) alguém fora da norma, fora da regra comum na política. Entre outras razões, pode-se explicar isso pelo fato de que sua entrada no governo se deu em meio a um conflito importante entre diversos setores poderosos da Argentina, como as corporações midiáticas e setores agropecuários, cenário muito diferente daquele vivido por Néstor Kirchner. Ela foi a primeira mulher eleita presidente na história da Argentina apesar de já termos tido uma presidenta, Isabel Martínez de Perón, esposa e vice de Juan Domingo Perón, que assumiu temporariamente seu cargo, no breve período de julho de 1974 a março de 1976. Assim, sua eleição correspondeu a uma mudança significativa na política e nos mostrou o quanto estávamos acostumados a uma política predominantemente masculina, associada ao corpo a corpo do espaço público, como algo próprio da ordem dos varões.

Um conjunto de condições de diferentes ordens afetou a afirmação de um seu estilo político coerente. Primeiro, porque ela teve de lidar com certas restrições que os homens em geral não têm. Já nas primeiras avaliações de sua imagem e do modo como se expressava ao povo, ela foi comparada a uma professora, ou seja, lhe foi atribuído um estilo professoral, pedagógico. Após a morte de Kirchner, o foco foi posto em uma sua apresentação humanizada, de viúva que sofria sinceramente e que, em função disso, ficava isolada no poder, rodeada de 'cortesãos' prestes a traí-la. A morte de Kirchner significou uma mudança radical nas representações que os cidadãos compartilhavam a respeito dela. Simultaneamente, ela teve de lidar com o uso, até então inédito, das redes sociais como estratégia de contato e comunicação com o povo argentino. Os políticos de sua geração, assim como ela própria, tinham vivido, experimentado a política em uma ecologia midiática bem diferente. Durante o período que presidiu o país foram muitos os desajustes entre suas estratégias de comunicação e as lógicas midiáticas que então prevaleciam. Tudo isso, sem dúvida, desempenhou papel decisivo na caracterização de seu ethos político.

Entrevistadores: Tendo em vista a complexidade dos estilos de comunicação desses sujeitos, haveria traços que lhes seriam mais característicos? Além disso, poderíamos dizer que em parte eles dizem respeito particularmente à cultura argentina ou se trata de um fenômeno internacional? 
Mariano Dagatti: Penso que a diferença fundamental entre o Kirchnerismo e o Cambiemos ${ }^{4}$ seja, respectivamente, a de uma representação pública da política como algo grandioso, extraordinário e transcendente, e da política como algo cotidiano, pragmático. Tenho a impressão de que o Cambiemos construiu sua identidade e seu espaço político, com base no valor eufórico do 'presente', em torno da ideia de uma Argentina moderna, empreendedora, pró-ativa, e não tão carregada pelo peso e pelo lastro de tradições, de um passado que estaria carregado ideologicamente e que levaria, diante das novas questões e problemas, a encontrar respostas antigas e inadequadas, a repetir o passado, enquanto o Kirchnerismo construiu sua identidade política apoiando-se no 'passado', mas este concebido como uma escola fundamental para pensar o presente, para balizar o presente, inscrito em certas tradições da vida política argentina, em especial no Peronismo ${ }^{5}$, mais especificamente, no Peronismo à esquerda.

Nesse sentido, o que aconteceu com o Kirchnerismo se difere de outros governos que representaram o denominado giro à esquerda. Acredito que haja um conjunto de estratégias comuns nos governos de direita e centro-direita, diretamente associados para construir fortemente a ideia de que as políticas sociais são um custo para a sociedade em seu conjunto e de que isso corresponde a um tipo de gasto 'populista', demagógico, responsável pelo aumento orçamentário de despesa pública, que em última instância equivaleria a uma forma de corrupção, de desvio do papel do Estado e de uso indevido desse dinheiro que deveria ser usado para lidar com muitos problemas sociais. Parece-me que a direita, com um forte respaldo dos principais meios de comunicação, empreendeu uma luta com muita convicção para impor certos sentidos comuns dentro de uma batalha cultural. Isso acontece na Argentina, no Brasil, no Chile, na Colômbia, no Paraguia e também no Uruguai. Em relação a isso, há muitas semelhanças no atual cenário Latino Americano.

Portanto, para entendermos o Kirchnerismo, é inevitável pensarmos o Peronismo, e o Peronismo impede uma divisão tão nítida entre esquerda e direita, uma vez que há peronismo de esquerda, peronismo de direita, peronismo centrista, e também, é claro, anti-peronismo de direita, de centro, de esquerda. Para muitos militantes políticos dos anos setenta, o Peronismo era o caminho para o Socialismo Nacional; para outros, nesses mesmos anos, significava ordem, paz e reconciliação nacional, depois de quase 20 anos de instabilidade política, golpes militares e o exílio de Perón. Para a maioria da minha geração, que éramos meninos ou

\footnotetext{
4 “Cambiemos" é o nome dado a uma coalização política de centro-direita criada em 2015 para escolher e apoiar como candidato à presidente Mauricio Macri.

${ }^{5}$ É o período que compreende os anos de 1946 a 1955 e 1973 a 1974 quando Juan Domingo Perón era então presidente da Argentina
} 
estudantes nos anos 90, o Peronismo adotado por Menem era o signo da experiência neoliberal na Argentina. O Kirchnerismo reivindicou o Peronismo de esquerda.

Falar em Peronismo é, por isso, lutar por um sentido do Peronismo, já que ele recebe críticas da direita mas também da esquerda. Por exemplo, muitos comunistas e troskistas acham que o Kirchnerismo foi uma armadilha dos capitalistas para se perpetuarem no poder.

Algo que chama atenção no Brasil é o fato de não se falar em "Lulismo", embora a expressão exista. Se fala amplamente em "PT", "Petismo", "Petistas". O modo como nomeamos na Argentina essas correntes políticas sugere uma concepção mais orgânica ligada ao político, de forma que na Argentina os movimentos populares exprimem a adesão ao homem político, ou seja, apenas falamos de Kirchnerismo em função de Kirchner e do Peronismo em função de Péron. Essa me parece ser uma diferença fundamental.

Voltando à questão dos estilos de comunicação, e se isso se trata de um fenômeno argentino ou de um fenômeno internacional, eu diria que há uma espécie de processo de avanço de certas lógicas de comunicação próprias da vida privada que se impõem à vida pública, e que geram novos mecanismos de interpelação dos cidadãos e eleitores na comunicação política. Um exemplo disso é o do apagamento das assimetrias entre os políticos e o povo, entre representantes e representados, e uma ampliação do que se dizia convencionalmente em política ao se incorporar toda uma série de tópicos que são próprios da vida privada e dos assuntos privados, que passam agora a ser entendidos como parte de uma lógica política. Esse fenômeno se dá na Argentina, no Brasil, bem como na maioria dos países da região, assim como em certos países da Europa, na França, notavelmente. O surgimento e desenvolvimento das mídias digitais e das redes sociais digitais contribuíram decisivamente com esse fenômeno na política, que já se observava desde os anos 90, na América Latina, com o auge da televisão.

\section{Política, Mídia e Tecnologias digitais}

Entrevistadores: $\mathrm{Na}$ esfera dos meios de comunicações, qual seria o papel da mídia tradicional na construção da imagem dessas figuras políticas da atualidade e em que medida isso se altera com as novas formas de produção e circulação do discurso político proporcionadas pelas tecnologias digitais? 
Mariano Dagatti: A atualidade das notícias, das informações é um objeto elaborado pela mídia. Então, é lógico que as figuras políticas da atualidade sejam notícia e sejam também figuras afetadas pelos efeitos da mídia. O semiólogo argentino Eliseo Verón dizia: "Esse objeto cultural que chamamos atualidade tem o mesmo status que um automóvel: é um produto, um objeto fabricado que sai dessa fábrica que é uma mídia informativa". E acrescentava: "Os meios não copiam nada (nem pioram, nem melhoram): produzem realidade social". Assim, certamente, cada país, cada região, cada estado, cada cidade tem atualidades com diferentes nuances. Na Argentina, quem vive em Buenos Aires tende a fazer uma leitura comum, ou buenos-aires-cêntrica dos fenômenos políticos. No entanto, quando se observa os jornais mais vendidos na Argentina, dois deles são jornais que não são de Buenos Aires, mas sim do interior. Um deles é La voz del interior, de Córdoba, o outro é La Gaceta, de Tucumán. Assim, as mídias tradicionais são aquelas que operam em Buenos Aires, e isso já supõe uma entrada enviesada na análise.

Em relação ao Kirchnerismo, é interessante ressaltar que dois dos principais meios de comunicação, Clarín - que equivale à Globo no Brasil -, e La Nación - jornal tradicional dos setores conservadores, agropecuários, liberal-conservadores na Argentina - foram diferentemente críticos.

La Nación foi desde o primeiro dia um crítico severo do Kirchnerismo. Já o Clarín, de início, estabeleceu uma boa relação com o governo, o que mudou quando assumiu Cristina Fernández, que durante seu mandato enfrentou dificuldades que Kirchner não teve de lidar, em sua relação com os meios de comunicação. Portanto, nos anos de 2007 a 2015, período que compreende o mandato de Cristina Fernández, as duas principais corporações midiáticas adotaram uma postura profundamente crítica do governo, centrada sobretudo na ideia de corrupção, de populismo, de gigantismo do Estado e de seu enorme gasto social.

Ao mesmo tempo, temos o Página/12, nascido na década de oitenta como um jornal de esquerda, crítico de todo processo neoliberal, e que durante o Kirchnerismo se converteu em porta-voz oficial do governo. Isso gerou um cenário na esfera jornalística impressa, estendendo-se também à televisão e rádio, que culminou no convívio de dois mundos alternativos, segmentados, nos quais os cruzamentos entre os leitores e os espectadores desses meios eram cada vez menos frequentes. Desse processo, advinha dois relatos diferentes do presente e, portanto, do futuro e do passado.

Ainda hoje estamos vivendo essa situação, da qual participam as redes sociais, cujos contratos de leitura, no entanto, não são exatamente os mesmos ligados a esses meios de comunicação de massa, mas sim a certos jornalistas advindos de diferentes campos, como da 
cultura, da política ou da economia. Isso se deve ao fato de que muitos jornalistas têm contas do Facebook, do Instagram, do Twitter, que é a mais política das redes sociais na Argentina, gerando uma espécie de contrato entre jornalista e leitor, e não mais mediado prioritariamente pelos grandes jornais e revistas. Isso não significa que as narrativas que produzem são contrárias ou distintas daquelas que se gera nos meios tradicionais, mas sim que participam dessa esfera. Aliás, estamos, no momento, desenvolvendo uma pesquisa, em conjunto com a Professora Silvia Ramírez Gelbes, na qual se procura indagar o tipo de relação que os leitores ou espectadores dos meios estabelecem, simultaneamente, com os jornalistas-indivíduos.

Sendo assim, as pessoas não leem ou desacreditam de toda a informação contida em certo meio, mas acreditam em determinado jornalista. Isso segue gerando lógicas curiosas de relação com o jornalismo e com a verdade. O surgimento das redes sociais e o sistema digital permitiu uma democratização de vozes, mas ao mesmo tempo relativizou certos procedimentos habituais dentro do jornalismo para, por exemplo, confirmar que uma notícia é verdadeira ou não. As pessoas se veem envoltas em uma lógica na qual alguns retuítam uma informação sobre a qual não dispõem de nenhum dado concreto e a única relação que estabelecem com ela é de ordem ideológica.

A temática em torno das redes sociais digitais suscitam reflexões sobre se as redes sociais favorecem efetivamente a complexificação do cenário: se há cada vez mais vozes, mais leituras e, portanto, uma forma de democracia virtual ou se, pelo contrário, as redes replicam certas lógicas de polarização política, inclusive em uma escala maior que os meios de comunicação, e assim geram o que se chama de 'bolhas de informação', em que cada um de nós acaba consumindo, postando, tuitando aquela informação com a qual se sente identificado, deixando de fora a informação com a qual não se tem nenhuma relação ou não se sente identificado.

Atualmente, as notícias políticas resultam de uma confluência da mídia tradicional e das novas formas de produção e circulação do discurso político proporcionadas pelas tecnologias digitais. Pela primeira vez, cada político - do presidente até o prefeito de uma pequena cidade - tem a possisibilidade de promover e estabelecer uma relacão imediata com seus interlocutores, sem os jornalistas como mediadores. Do mesmo jeito, os cidadãos podem divulgar suas opinões na esfera pública sem ser preciso nenhum outro dispositivo a não ser um celular ou um computador. Somos testemunhas de uma esfera pública muito mais complexa e polifônica, mas ao mesmo tempo não necessariamente mais plural ou democrática, tal como observa Marc Angenot (1989), crítico enfático do que chama de "o mito democrático" da polifonia bakhtiniana. 


\section{Política, pós-verdade e formação do cidadão}

Entrevistadores: Que contornos ou especificidades a discussão em torno do tema da 'verdade' ganhou no contexto político da Argentina, levando em consideração a discussão recente sobre a 'pós-verdade', sua relação com as redes sociais e a política?

Mariano Dagatti: Há diferentes fenômenos aludidos nesta questão. Por um lado, se encontra o tema da 'verdade', que ganhou muito peso com a circulação do termo 'pós-verdade' nos últimos dois ou três anos, e ao qual se costuma associar sobretudo, e mesmo de uma maneira problemática, o papel das emoções na argumentação política. Haveria um processo no qual as emoções se impõem sobre a razão e, portanto, ficaríamos mais perto da mentira ou da tergiversação do que da verdade. Isso, no entanto, segundo alguns posicionamentos teóricos e metodológicos - por exemplo, em Plantin (2010) e "As razões das emoções" -, é muito difícil de sustentar, porque se supõe haver uma argumentação em que não estejam implicadas as paixões, que seria ataráxica. Isso é muito difícil de sustentar teoricamente assim como na prática, porque até o tédio é uma paixão, como o ódio é uma paixão.

Então, quando se fala em'pós-verdade', em geral se relaciona a questão ao uso político recente do termo, para se referir, por exemplo, ao que ocorre atualmente nos Estados Unidos, com Trump.

Acredito que há um fenômeno diferente, que me parece mais interessante, acerca da relação entre o verdadeiro e o verossímil em sociedades democráticas e em sociedades onde a opinião pública tem um peso central na configuração do nosso senso comum. Barthes (1993), quando no meio dos anos sessenta escrevia sobre a Retórica Antiga, falava justamente que Aristóteles era um pensador dois milênios adiantado a sua época, porque era capaz de pensar já, não o verdadeiro, mas como se constrói o verossímil na opinião pública. Parece-me que é um tema que não é novo, que já existe historicamente e que tem diferentes matizes quando estamos falando de um sistema democrático ou de um sistema ditatorial ou de outro.

Sem dúvida, o papel dos meios de comunicação tem estado no olho do furacão desde a década de trinta e quarenta, quando se discutia o poder de influência dos meios de comunicação sobre a opinião pública. É conhecida a utilização que os regimes totalitários fizeram da mídia. Essa discussão recaía sobre o estatuto da verdade do que era enunciado ou dos modos de um verossímil social, historicamente determinado. O novo em relação a esse tema hoje em dia é o fenômeno do sistema de informação com base na internet, nas redes sociais digitais. Verón (2013) chamava a isso "la revolución del acceso", um momento no 
qual cada um de nós pode se converter em agente de transmissão de informação a partir do acesso a um celular e à internet e, então, verter nossas opiniões, dizer nossas verdades, brindar nossos argumentos. O problema é que surge um terreno médio entre certas vozes autorizadas do jornalismo, da política, e uma espécie de rumor generalizado, que se expande justamente graças a esta lógica das redes sociais e que, obviamente, relaciona-se com certa interpelação ideológica. A direita foi na Argentina o primeiro espaço político que compreendeu a nova paissagem política. A esse respeito, a colega Ana Slimovich (2020) tem feito uma pesquisa extensa sobre a mediatização da política nas redes, levando em conta os casos do Kirchnerismo e, sobretudo, do $P R O$ (que se tornaria depois o principal partido da coalizão Cambiemos).

Nós tendemos, por exemplo no Twitter, a retuitar postagens (d)aqueles com quem compartilhamos uma certa visão de mundo, inclusive relativas a notícias sobre futebol, que não tem a ver com a vida política e social. Está demonstrado que retuitamos com mais ou menos velocidade se a notícia pertence a um meio ou fonte institucional que lemos ou que não lemos, porque há uma espécie de dissonância cognitiva entre um fenômeno e outro ${ }^{6}$. Portanto, basicamente acredito que é importante nos perguntarmos na atualidade pela 'verdade', mas não creio que este seja um problema novo. O que é novo, em todo caso, é o ecossistema sociomidiático no qual esse fenômeno se produz e circula.

Entrevistador: Que contribuições as pesquisas dedicadas aos discursos políticos podem apresentar para o ensino na sala de aula?

Mariano Dagatti: Acredito que as discursividades políticas e midiáticas atravessam nossa vida cotidiana e, por isso, trabalhar uma leitura crítica, tanto das discursividades políticas como das midiáticas, é fundamental para a construção da cidadania. O que nos leva a outra pergunta: que papel têm as universidades ou a escola de ensino médio nas nossas democracias? As respostas que dermos a esses questionamentos qualificará o papel da leitura crítica dos meios midiáticos e da política como mais ou menos relevantes. Eu me lembro, embora faça já algum tempo, a entrevista que fizemos com o filósofo Jean-Luc Nancy (2011) e nela ele nos disse:

\footnotetext{
${ }^{6}$ A esse respeito, cf. Aruguete e Calvo (2018). Mais recentemente, em meio à pandemia, os autores acabam de lançar sobre este tema o livro: Fake news, trolls y otros encantos. Cómo funcionan (para bien y para mal) las redes sociales.
} 
¿Ser educado en qué y para qué? Educamos a la población para aquello que precisa el sistema técnico-capitalista. ¿Y si dejamos esa instrucción a las empresas, a las profesiones, y que la política tenga por función permitir el acceso de todos a la educación intelectual y artística??

Atualmente é uma matéria fundamental de qualquer profissão, não somente das carreiras sociais, dispor de estudos que ponham em xeque o senso comum e o modo como se constrói a verdade na política, nos meios de comunicação, na nossa sociedade, quanto ao trabalho, à família e à própria educação. Responder a essa pergunta nos leva a nos questionar acerca de que tipo de universidade e de que tipo de sistema educativo queremos: formar mão de obra para o mercado ou cidadãos, com vistas a construir um mundo melhor.

\section{Referências}

ANGENOT, Marc. El discurso social: problemática general. In: 1889 - Un état du discours social. Québec: Éditions du Préambule, 1989, p. 13-39.

ARUGUETE, Natalia; CALVO, Ernesto. Redes sociais e política na Argentina. EID\&A Revista Eletrônica de Estudos Integrados em Discurso e Argumentação. v. 1, n. 16, p. 299313, 2018. Disponível em: <http://periodicos.uesc.br/index.php/eidea/article/view/2224>. Acesso em: 7 abr. 2020. DOI: https://doi.org/10.17648/eidea-16-2224

ARUGUETE, Natalia; CALVO, Ernesto. Fake news, trolls y otros encantos. Cómo funcionan (para bien y para mal) las redes sociales. Buenos Aires: Siglo XXI Editores, 2020.

BARTHES, Roland. La retórica antigua. Un prontuario. In: La aventura semiológica. Buenos Aires: Paidós, 1993, p. 85-160.

DAGATTI, Mariano; KRATJE, Julia; DRIVET, Leandro. Religiosidad y secularización. Entrevista com Jean-Luc Nancy. Revista Def-ghi. Comunicación y Arte, Buenos Aires, Ano IV, n. 4. p. 84-91, 2011.

PLANTIN, Christian. As razões das emoções. In: MENDES, Emília; MACHADO, Ida Lúcia (orgs.). As emoções no discurso. v. II. Campinas: Mercado de Letras, 2010, p. 57-80.

SLIMOVICH, Ana. El camino de 'Cambiemos' en las redes sociales: entre las lógicas políticas y las mediáticas. In: AYMA, Ana; DAGATTI, Mariano. La política en escena. Voces, cuerpos e imágenes en la Argentina del siglo XXI. Bernal: Editorial UNQ, 2020.

VERÓN, Eliseo. La semiosis social: ideas, momentos, interpretantes. Buenos Aires: Paidós, 2013.

\footnotetext{
7 "Ser educado em quê e para quê? Educamos a população para aquilo que necessita o sistema técnicocapitalista. E se deixarmos essa instrução às empresas, às profissões, e que caiba à política ter por função permitir o acesso de todos à educação intelectual e artística?".
} 
Mariano Dagatti (entrevista). Discurso político, mídia e verdade.

Recebido em: 12 de fevereiro de 2020.

Aceito em: 17 de abril de 2020. 